SISTEMA
ELETRONIICO
DE REVISTAS
SER I UfPR

\title{
Avaliação empírica de um instrumento de pesquisa socioambiental: a relevância do diagnóstico participativo
}

\section{Empirical evaluation of a socio-environmental research tool: the relevance of participatory diagnosis}

\author{
Ricardo ALMEIDA $^{1 *}$, Carlos Roberto Massao HAYASHI ${ }^{1}$ \\ ${ }^{1}$ Universidade Federal de São Carlos (UFSCar), São Carlos, SP, Brasil. \\ *E-mail de contato: ricalmeida1212@gmail.com
}

Artigo recebido em 29 de março de 2019, versão final aceita em 5 de dezembro de 2019, publicado em 1 de abril de 2020.

RESUMO: O objetivo deste artigo é analisar a aplicação de um instrumento de pesquisa e seu potencial de avaliação socioambiental em amostra populacional. Trata-se de um estudo transversal com amostragem por conglomerados (22 por 10), desenvolvido em uma comunidade do Estado de Minas Gerais, Brasil. Fez-se uso de questionário validado por juízes e estruturado em quatro dimensões pontuadas em escala de Likert. Os dados foram analisados por meio de técnicas descritivas com apoio do software SPSS Statistics 22.0. Foram entrevistados 226 moradores. A coleta de dados possibilitou a construção de indicadores socioambientais relevantes para subsidiar ações de educação ambiental no campo de estudo. Os principais desafios do cenário relacionaram-se à percepção afetiva das pessoas pelo ambiente; à destinação de resíduos eletrônicos e orgânicos; e à interação social entre comunidade e instituições locais. O instrumento de pesquisa apresentou viabilidade de aplicação e potencial de avaliação diagnóstica para subsidiar um plano de intervenção em ações de educação ambiental. Ademais, firmou-se como uma oportunidade de interação com o sujeito de pesquisa, despertando-lhe interesse para enfrentamento dos problemas identificados.

Palavras-chave: ciência, tecnologia e sociedade; instrumento de pesquisa; educação ambiental; diagnóstico participativo; intervenção socioambiental.

ABSTRACT: The aim of this paper is to analyze the application of a research instrument and its potential for social and environmental assessment in a population sample. This is a cross-sectional cluster sampling study (22 per 10), conducted in a community in the state of Minas Gerais, Brazil. We used a questionnaire validated by judges and structured in four dimensions punctuated in Likert scale. Data were analyzed using descriptive techniques supported by SPSS Statistics 22.0 software. 226 residents were interviewed. Data collection enabled the construction of relevant socio-environmental indicators to support environmental education actions in the field 
of study. The main challenges of the scenario related to the affective perception of people by the environment; the disposal of electronic and organic waste; and social interaction between community and local institutions. The research instrument presented application feasibility and diagnostic evaluation potential to support an intervention plan in environmental education actions. In addition, it was established as an opportunity for interaction with the research subject, arousing their interest to face the identified problems.

Keywords: science, technology and society; research instrument; environmental education; participative diagnosis; socio-environmental intervention.

\section{Introdução}

A participação da sociedade nos processos decisórios firma-se como base elementar para os estudos em Ciência, Tecnologia e Sociedade (CTS), sendo a pesquisa social um caminho promissor a ser trilhado nesse campo, haja vista que tanto a ciência quanto a tecnologia resultam das atividades humanas e, portanto, são construídas e situadas histórica e socialmente (Hayashi et al., 2014).

Um marco importante da história socioambiental refere-se aos estudos de Rachel Louise Carson, bióloga marinha, escritora, cientista e ecologista, que se dedicou aos estudos sobre a conservação ambiental no final da década de 1950. Em Primavera Silenciosa (Silent Spring), Carson (1969) discute os problemas causados pelo uso de pesticidas sintéticos nas plantações norte-americanas. A obra, que destoava do senso comum da época e transitava em um terreno fortemente dominado por homens e por uma ciência enrijecida que desprezava outros saberes (Bonzi, 2013), conquistou legitimidade e resultou em mudanças na política nacional de uso de pesticidas e na criação da Agência de Proteção Ambiental dos Estados Unidos.

Embora as normativas públicas sejam um importante instrumento para estímulo da participação social, representando, teoricamente, o maior poder de decisão sobre temas relacionados às questões so- cioambientais, nota-se um descompasso entre o que preconizam as políticas públicas e o comportamento, de ordem prática, tanto das organizações quanto da própria sociedade civil, deixando em evidência a dicotomia teoria/prática que atua como barreira no desenvolvimento da cultura de sustentabilidade (Almeida et al., 2017).

Nesse sentido, é possível observar que, no cenário da vida real, os problemas ambientais geram preocupações tanto na comunidade científica quanto na população em geral. Entretanto, o comportamento humano mostra-se resistente a mudanças, ainda que os dispositivos legais do Estado estabeleçam as diretrizes para que esse quadro seja revertido (i.e., Política Nacional de Educação Ambiental, Política Nacional de Resíduos Sólidos, Agendas Ambientais, dentre outros Programas de mobilização social). Para Hannigan (1997) a percepção social e o próprio debate sobre as questões ambientais dependem de fatores que estão relacionados à cultura, aos processos de comunicação e ao conhecimento dos sujeitos sociais.

Discussões mais recentes, coordenadas pela Organização das Nações Unidas (ONU), enfatizam a importância da construção de modelos de cooperação entre governos, iniciativa privada e sociedade civil para promoção do desenvolvimento sustentável, reforçando a importância de haver ações que adotem uma postura mais aberta ao diálogo, que formem parcerias mais efetivas e, sobretudo, que estimulem 
o uso de dinâmicas mais proativas para envolver a sociedade.

Um dos instrumentos brasileiros constituído de diretrizes que dão ênfase ao desenvolvimento de trabalhos coletivos na vertente socioambiental refere-se ao Caderno Metodológico do Ministério das Cidades. Trata-se de um material elaborado em parceria com os Ministérios do Meio Ambiente, da Educação, da Saúde e da Integração Nacional, cujo objetivo é estimular a participação ativa e organizada dos diversos atores sociais em processos de educação ambiental e mobilização social em saneamento (Brasil, 2009).

As metodologias apresentadas nesse material baseiam-se em temas que enfatizam o desenvolvimento de ações articuladas de educação e mobilização, caracterizadas pela participação popular e o compromisso com mudanças estruturantes. Propõe subsidiar as interações necessárias para condução de projetos socioambientais aplicados no coletivo, e ressalta a importância de agregar novas alternativas ao seu conteúdo, de modo que os conhecimentos não permaneçam estáticos e que estejam sempre em sintonia com as peculiaridades locais.

Dentre as estratégias que formam a base de atuação desse Caderno, o diagnóstico participativo firma-se como etapa fundamental no processo de articulação social e contribui para identificação de cenários, problemas e potencialidades da realidade na qual se pretende atuar. Para tanto, o documento destaca a importância de se ter objetivos claros e metodologia apropriada para atingi-los, seja utilizando técnicas mais simples, como observar aspectos relevantes, ou sofisticadas, que buscam maior aprofundamento no conhecimento da realidade.

Utilizar instrumentos de pesquisa para entendimento da realidade, sem prescindir da participação comunitária e abordando dimensões socioambientais a partir de temas-geradores baseados, dentre outros, na dotação de infraestrutura em saneamento, coleta e disposição final de resíduos, práticas de educação ambiental e uso de tecnologias sociais, representa o início de articulações potencialmente frutíferas para identificar os desafios locais existentes. Da mesma forma, pode ser uma importante ferramenta para obtenção de indicadores capazes de apontar os melhores caminhos a serem adotados no processo de enfrentamento dos problemas socioambientais mais relevantes (Brasil, 2009).

O objetivo deste estudo foi analisar a aplicação de um instrumento de pesquisa socioambiental e seu potencial de avaliação em uma população amostral, cuja finalidade consistiu em realizar um diagnóstico participativo para subsidiar processos de mobilização social e intervenção em práticas de educação ambiental em uma comunidade localizada na região do Triângulo Mineiro (Minas Gerais, Brasil).

\section{A construção coletiva do conhecimento}

A participação da sociedade na construção de políticas públicas ainda é caracterizada pela superficialidade, não oferecendo oportunidades para que os questionamentos ocorram da forma como deve ser um processo participativo, sendo necessário, portanto, persistir na construção de processos democráticos que superem a veia autoritária e revelem as diferenças existentes entre ser consultado, ser ouvido e ser coautor do processo (Costa et al., 2009).

Historicamente, diversas correntes teóricas fundamentaram a produção do conhecimento enquanto construção humana, traçando uma trajetória em que a busca por explicações fez emergir novos pensamentos e contribuiu para revolucionar a forma de compreender a organização da sociedade. 
À guisa de síntese, um marco histórico importante que ajuda a contextualizar a construção humana do conhecimento é revisitado por Bittar \& Ferreira Jr. (2014) ao descreverem algumas perspectivas do marxismo, corrente teórica do século XIX que imprimiu um caráter inovador na produção do conhecimento, sob a afirmativa de que é a realidade histórica (material) que exerce domínio sobre o campo das ideias (fator subjetivo), e não o contrário.

Essa concepção, de acordo com esses autores, permitiu às ciências humanas interpretar que as mudanças históricas resultam de lentos processos sociais, econômicos e políticos, assim como os fenômenos humanos são resultado de contradições sociais. Instalava-se, então, um novo método de investigação da realidade histórico-social, reforçando a noção de que os fatos da humanidade são historicamente determinados.

O século $X X$, por sua vez, foi um cenário de grandes revoluções científicas e de significativas transformações no arranjo social, haja vista que modernas teorias científicas foram transformadas em tecnologias aplicadas, com uso principalmente na indústria. No entanto, apesar dos impressionantes avanços tecnológicos terem influenciado os processos produtivos, o poder imponente da ciência e tecnologia revelou-se ao mundo, de forma assustadora, durante a segunda Guerra Mundial (1944-1946), com a utilização de bombas nucleares (Bittar \& Ferreira Jr., 2014).

Esse período impactante além de trazer certo desencantamento por parte da comunidade científica contribuiu para o surgimento de fenômenos sociais constituídos de preocupantes contradições: a automação da indústria e o desemprego; o acúmulo de capital e a exclusão social; a revolução tecnológica e as catástrofes ambientais. Em Neder (2015) tem-se que esses fatos desencadearam na sociedade sentimentos de medo e apreensão de que a ciência se perdesse ainda mais em sua dimensão de liberdade, criatividade e neutralidade na maneira de produzir conhecimento.

Salles \& Matos (2017) destacam que aspectos relevantes instalados na construção do conhecimento recebem uma atenção especial em Edgar Morin, que rejeita respostas simples aos múltiplos problemas do planeta e assevera que a ciência trouxe cura para inúmeras doenças, mas também armas e morte; criou a alta tecnologia, mas não cuidou com a mesma intensidade da desigualdade de acesso a ela e; transformou-se em instrumento de poder nas mãos das grandes corporações e de governos.

A teoria da complexidade, pautada em Morin, busca compreender as questões que desafiam os rumos do conhecimento científico e tecnológico do século XXI. Em Salles \& Matos (2017) a complexidade firma-se como uma teoria que reflete sobre o desenvolvimento humano e a sustentabilidade no cotidiano moderno, e enfatiza a necessidade de humanização no encontro entre ciência, tecnologia e sociedade. O pensamento complexo ganha destaque no cenário dos enfrentamentos socioambientais ao abordar os dilemas éticos e sociais nas questões de democratização do saber e a não fragmentação do ensino para explicar os problemas sociais e os impactos ambientais causadores de mortes e miséria no mundo.

Nesse contexto, percebe-se que o processo de construção do conhecimento consiste em um cenário que reúne consensos, avanços, dissensos e retrocessos, revolucionando a forma de entender os fenômenos existentes na história da sociedade humana. E é justamente essa dinâmica que define a característica colaborativa da ciência moderna, 
constituindo seu caráter democrático a partir de mecanismos que dão voz à dimensão social, corroborando à sociedade seu espaço na produção do conhecimento, bem como sua participação nos avanços científicos.

Gregolin et al. (2008) consideram que as inter-relações da ciência e tecnologia com a sociedade perpassam por influências e interesses das organizações e dos indivíduos, sendo necessário, portanto, metodologias que viabilizem a participação dos múltiplos atores sociais nos processos que definem as políticas públicas, a inovação e os demais efeitos tecnológicos e científicos. Uma das formas de tornar isso possível, segundo esses autores, é fazendo uso de estudos de prospecções que, sob condições éticas e com participação de especialistas, sejam capazes de gerar informações relevantes (p.ex., entrevistas e questionários).

As investigações científicas utilizam diversas metodologias para desenvolvimento de estudos que envolvem a participação da sociedade. Em vista disso, a noção de construção coletiva do conhecimento materializa-se nas técnicas que são escolhidas para coleta de dados, conforme requer o tema ou o objeto de estudo, e firma-se como um avanço da pesquisa social no processo de compartilhamento do saber na vida comunitária (Brandão, 2003).

Esse método participativo é sustentado por Thiollent (2011) como ponto de partida para a articulação entre o conhecimento que é produzido e o processo de enfrentamento dos problemas sociais. Brandão \& Borges (2007) enfatizam que o campo das ações ambientais é o que mais se destaca com o uso dos métodos participativos, uma vez que as investigações se formam com mais criatividade, conferindo melhor associação ao coletivo. Silveira \& Córdova (2009), por sua vez, destacam a oportu- nidade que é dada ao pesquisador de aproximar-se e entender a realidade escolhida para investigação, assim como obter subsídios para fazer intervenções no cenário real.

\section{A participação social na ciência e tecnologia}

As consequências negativas resultantes da aplicação autônoma da ciência e tecnologia nos meados do século XX abriram portas para o debate público fazendo com que a participação social passasse a assumir um papel relevante na contemporaneidade. Entretanto, a democratização da ciência e tecnologia envolve controvérsias que desafiam o processo de difusão do conhecimento na sociedade.

Para Atienza \& Luján (1997) é um grande equívoco associar as consequências deflagradas no uso da ciência e tecnologia à falta de conhecimento científico da população. Lopez Cerezo (2005) defende que as polêmicas sociais se deram pelo fato de que o cidadão não detém o conhecimento técnico e científico do objeto de estudo. Esse autor enfatiza que a cultura científica deve ser crítica e responsável, sobretudo, deve considerar as questões éticas e a consciência do uso político da ciência no âmbito público, de modo que a própria sociedade consiga fazer uso das informações na tomada de decisão em seu cotidiano, seja em uma simples compra no supermercado ou no uso de uma tecnologia médica, seja na condição de consumidor ou de empresário. Propõe, ainda, que o enfrentamento a essa questão deve ser feito pela aproximação da ciência com os cidadãos e pelo direcionamento das políticas públicas para atendimento às demandas sociais com abertura de espaço para as opiniões e participação social. 
Alcíbar (2015) destaca que iniciativas adotadas por países democráticos devem ser mais observadas, haja vista que são cenários que contemplam o diálogo entre ciência e sociedade. Para ele, desafios e dilemas podem ser constatados a partir de um panorama empírico, que constitui em oportunidade concreta para verificar a legitimidade do público como ator social que reflete, critica e participa das tomadas de decisão.

Alguns modelos de democracia ajudam na compreensão sobre o que é, de fato, uma ciência participativa, a exemplo das democracias baseadas em conflitos de elites ou das democracias pluralistas, que atendem interesses voluntários de grupos; e as democracias participativas, que envolvem a comunidade de forma mais significativa nas decisões. Sobre isso, Foltz (1999) assevera que, seja qual for o modelo, aumentar o nível de participação da sociedade na ciência constitui-se um passo importante na direção certa.

Rowe \& Frewer (2000) consideram que há pouca divulgação sobre o exercício prático da participação pública na literatura científica, o que proporciona ao tema um caráter de superficialidade em detrimento das propostas e implementações que resultam desse exercício. Esses mesmos autores dividem os critérios de avaliação da participação pública em duas categorias: de aceitação e de processos. Embora ambos os critérios sejam necessários para o método de avaliação, apresentam distinções entre si e podem ser aplicados sob diferentes circunstâncias. Os critérios de aceitação envolvem representatividade da população, influência e transparência, enquanto os critérios de processo abordam acessibilidade de recursos, definição de tarefas e tomada de decisão.
Sendo assim, de acordo com Rowe \& Frewer (2000), diferentes necessidades requerem abordagens distintas e, portanto, deve-se preconizar o aprimoramento das articulações no sentido de melhorar as ações de consultar, de ouvir e direcionar os trabalhos para resultados que respondam às expectativas da comunidade participante.

\section{Métodos}

A pesquisa foi realizada em um município do Estado de Minas Gerais, Brasil, cuja população é superior a 300 mil habitantes (IBGE, 2018). O diagnóstico concentrou-se em um bairro da cidade, que, de acordo com a prefeitura local, é constituído de aproximadamente 9 mil moradores.

A elaboração do instrumento foi baseada em revisão de literatura realizada a partir de estudos sobre métodos sistemáticos para desenvolvimento de pesquisas sociais, considerando as etapas de estrutura conceitual, objetivos, população envolvida, itens e escalas do instrumento, processo de validação e pré-teste (Coluci et al., 2015).

$\mathrm{O}$ instrumento foi estruturado em duas partes, sendo a primeira destinada à caracterização da amostra e a segunda parte composta por 44 questões fechadas, distribuídas em quatro dimensões que formaram os temas-geradores para o diagnóstico: infraestrutura, hábitos cotidianos, interatividade com as instituições locais, produção e destinação de resíduos. Fez-se uso da escala de Likert, com cinco opções de resposta preestabelecidas pontuadas de 1 a 5 , onde 1 significa a opção menos favorável e 5 a mais favorável.

O processo de adequação e coerência dos itens foi verificado e submetido à avaliação de 
juízes ${ }^{1}$ especialistas na temática. Foram adotados procedimentos qualitativos para avaliação dos itens do instrumento, utilizando cinco critérios: organização, objetividade, clareza, facilidade de leitura e compreensão do conteúdo. Foi conferida aos juízes a oportunidade de redigir comentários e sugestões para aprimorar a qualidade do instrumento. Os ajustamentos foram concluídos após as correções orientadas pelos avaliadores, seguidos de adaptações semânticas oriundas da etapa de pré-teste, que envolveu membros da comunidade e sujeitos da realidade focalizada.

Para cálculo da amostra foi utilizado o processo de amostragem por conglomerados, que é uma técnica probabilística na qual as unidades amostrais são grupos de elementos (Haddad, 2004). O tamanho da amostra foi calculado pela equação: $\mathrm{n}=\left\{2,0\left[\mathrm{z}^{2} \mathrm{p}(-\right.\right.$ 1-p) / d $\left.\left.{ }^{2}\right]\right\}$, onde, n é o tamanho da amostra; 2,0 é a estimativa do efeito do desenho para amostras por conglomerados; $\mathrm{z}^{2}$ corresponde ao limite de confiança de $95 \%$; p corresponde à proporção populacional, estimada em $50 \%$ ou 0,50 ; d é a precisão desejada, estabelecida em $10 \%$ ou 0,10 . Assim, a amostra mínima resultou em: $\boldsymbol{n}=\mathbf{1 9 2 , 0 8}$. Por conseguinte, estimou-se uma proporção de perdas (h) equivalente a $10 \%$ ou 0,10 do valor de n, utilizando a equação: $\boldsymbol{n}$ $+\boldsymbol{h}$. Assim, definiu-se o total de 212 entrevistados.

O processo de amostragem foi realizado em 2 estágios. No primeiro, a partir do mapa do bairro, identificou-se a composição geográfica de 22 ruas, que constituíram os conglomerados da amostragem. No segundo, determinou-se que 10 residências seriam incluídas em cada conglomerado, sendo entrevistada apenas uma pessoa por domicílio. Assim, a técnica de amostragem consistiu na proporção 22 por 10 para estimar a população total pretendida (212 respondentes).

Para selecionar os participantes da pesquisa optou-se em utilizar a técnica de amostragem sistemática, que consiste em escolher os sujeitos que constituirão a amostra, considerando um intervalo fixo entre eles (Bolfarine \& Bussab, 2005). Esse intervalo $(\mathrm{k})$ é calculado dividindo-se o tamanho da população $(\mathrm{N})$ pelo tamanho da amostra (n), representado pela equação $\mathrm{N} / \mathrm{n}=\mathrm{k}$, onde, admitindo-se que k seja um número inteiro, faz-se então um sorteio aleatório entre os números sequenciais $(1,2, \ldots \mathrm{k})$, obtendo assim um valor denominado semente inicial, que será utilizado como fator de repetição, constituindo-se como intervalo fixo entre as residências e, consequentemente, para seleção dos respondentes.

A partir dos cálculos da amostra e definidas as técnicas de amostragem, deu-se início aos procedimentos de coleta de dados junto aos moradores da comunidade. Previamente à abordagem dos sujeitos, as residências sorteadas receberam um convite à pesquisa, contendo explicações básicas sobre o estudo, tais como: procedência, finalidade, assunto tratado e contato dos pesquisadores. Posteriormente, os moradores que concordaram em participar da pesquisa foram entrevistados. A coleta de dados contou com a participação de universitários dos cursos de Psicologia e Engenharia Ambiental, sob a supervisão e coordenação dos autores deste artigo. Os sorteios de residências foram realizados até que fosse alcançado o número previsto no cálculo da amostra.

O projeto foi aprovado pelo Comitê de Ética em Pesquisa (Protocolo 2017.436), em conformida-

\footnotetext{
${ }^{1}$ A comissão de juízes foi composta de docentes com titulação de doutorado nas áreas de conhecimento das Ciências Sociais e das Ciências da
} Saúde (Saúde Coletiva e Saúde Alimentar). 
de com a Resolução 196/96 do Conselho Nacional de Saúde. Os participantes assinaram termo de consentimento livre e esclarecido no momento da entrevista, atendendo os preceitos éticos da pesquisa científica e validando a base amostral do estudo. Os dados foram tabulados em planilha eletrônica e analisados por técnicas descritivas apoiadas pelo software SPSS Statistics versão 22.0.

\section{Resultados}

Foram entrevistados 226 moradores, superando a amostra mínima calculada (de 212 respondentes) em razão da simultaneidade de coleta realizada pelos entrevistadores em algumas ruas da comunidade, observada a abordagem de diferentes residências. De acordo com os dados apresentados na Tabela 1, a média de idade dos entrevistados foi de 47 anos; renda familiar variável entre 1 e 15 salários-mínimos; média de 3 moradores por residência e o tempo aproximado de 21 anos de residência na comunidade.

Conforme apresentado nas Figuras de 1 a 4, a amostra constituiu-se de $87(38,50 \%)$ respondentes do sexo masculino e $139(61,50 \%)$ do sexo feminino. Os maiores indicadores de caracterização da população incidiram sobre o nível de escolaridade: Ensino Médio
$(39,82 \%)$ e adeptos à religião católica $(49,56 \%)$. O índice de trabalhadores ativos foi de aproximadamente $80 \%$, dentro de uma diversidade de profissões.

Quanto à situação de moradia, 172 respondentes afirmaram residir em imóvel próprio $(76,11 \%)$, enquanto os demais, 54 (23,79\%), pagam aluguel. Desse total, $41(18,14 \%)$ desejam mudar-se de bairro, motivados pela possibilidade de aquisição de novo imóvel (7,08\%), insatisfação com o bairro $(3,10 \%)$, dificuldades de locomoção para o trabalho ou escola $(2,21 \%)$ ou por outros motivos $(5,75 \%)$.

No intuito de conhecer o nível de percepção espacial e afetiva que os moradores estabelecem com os espaços da sua própria comunidade, os entrevistados foram questionados sobre ter conhecimento da história do surgimento do bairro. Apenas 52 pessoas (23\%) afirmaram ter conhecimento, enquanto a maioria, $77 \%$ dos respondentes, revelou que desconhece a história da origem do bairro. Estimulados a indicar um lugar que gostam ou acham mais bonito no bairro e um lugar que menos gostam, $70(30,97 \%)$ tiveram dificuldade para indicar um local bonito e 141 (62,39\%) não conseguiram indicar um local de que não gostam.

Por fim, perguntados sobre qual é o principal responsável por cuidar do meio-ambiente, 98 respondentes $(43,36 \%)$ afirmaram que a própria sociedade

TABELA 1 - Análise descritiva da amostra de respondentes.

\begin{tabular}{lcccccc}
\hline \multicolumn{1}{c}{ Variável } & $\mathbf{N}$ & Média & Desvio-padrão (dp) & Mínimo & Máximo & Coeficiente de variação \\
\hline Idade & 225 & 47,13 & $\pm 15,93$ & 18,33 & 86,59 & 33,80 \\
Renda familiar & 223 & $3.633,18$ & $\pm 2.365,34$ & 900,00 & $15.000,00$ & 65,10 \\
Pessoas residência & 226 & 3,32 & $\pm 1,31$ & 1 & 9 & 39,42 \\
Tempo residência & 226 & 21,23 & $\pm 16,54$ & 1 & 69 & 77,88 \\
\hline
\end{tabular}

FONTE: Elaborada pelos autores, 2018. 


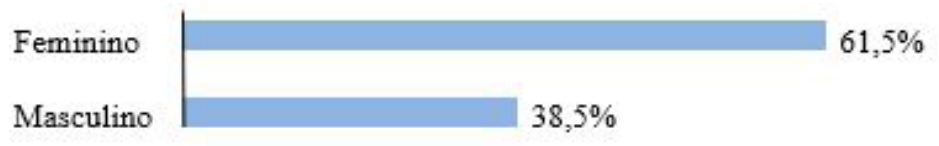

FIGURA 1 - Caracterização dos respondentes, por sexo.

FONTE: Elaborada pelos autores, 2018.

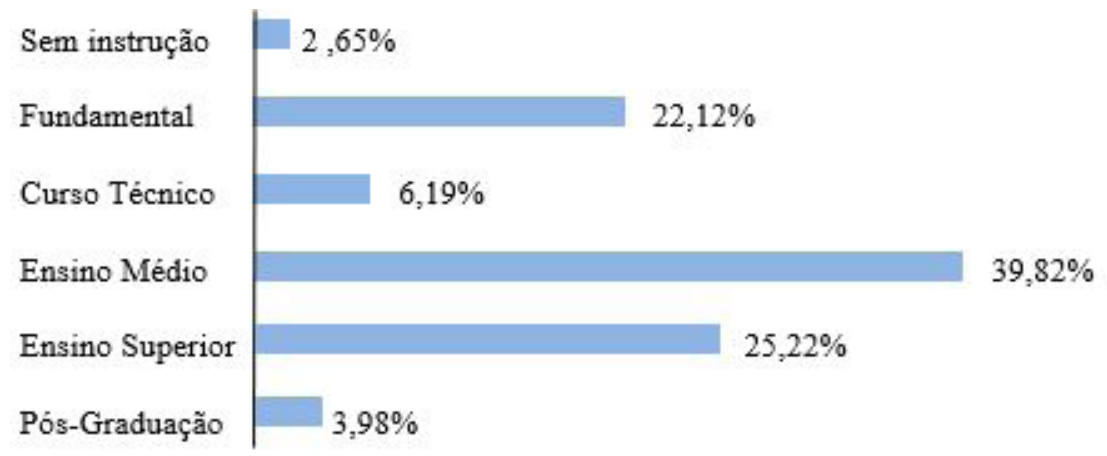

FIGURA 2 - Nível de escolaridade da amostra de respondentes.

FONTE: Elaborada pelos autores, 2018.

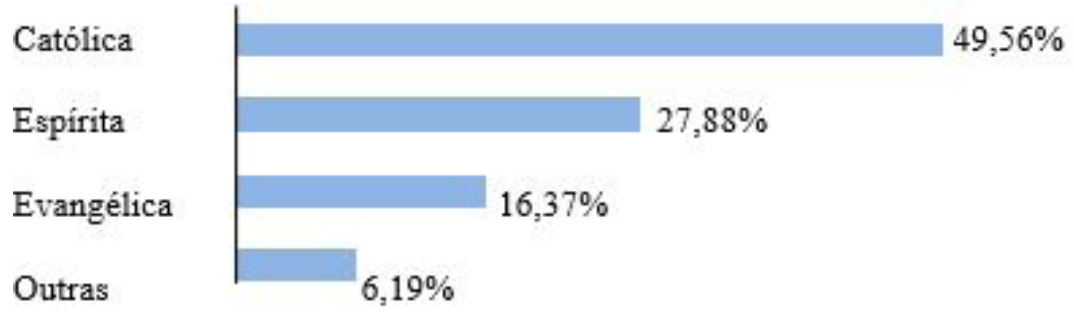

FIGURA 3 - Caracterização da população de acordo com a opção religiosa.

FONTE: Elaborada pelos autores, 2018. 


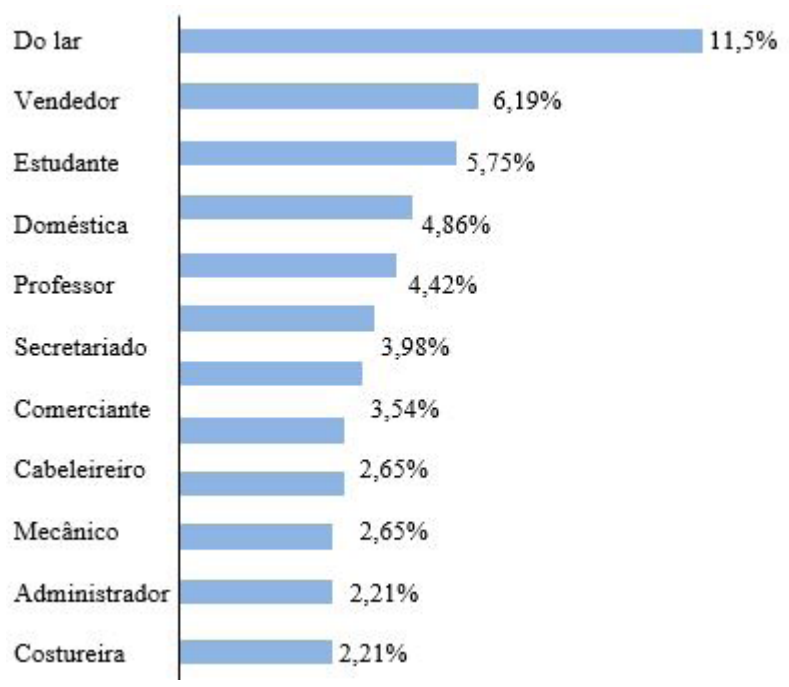

FIGURA 4 - Caracterização da população conforme atuação profissional.

FONTE: Elaborada pelos autores, 2018.

deve assumir esse papel, superando a indicação sobre 0 governo (15,04\%) e a escola (2,31\%). Tal perspectiva foi reforçada quando questionados sobre o interesse em participar de ações voltadas para o enfrentamento dos problemas socioambientais da comunidade, $128(56,64 \%)$ declararam-se dispostos a fazer parte de algum projeto com esse propósito; 42 (18,58\%) demonstraram dúvidas na participação; 40 (17,70\%) afirmaram não ter tempo para participar desse tipo de trabalho e 16 (7,08\%) disseram não ter interesse em atuar sobre o tema.

A segunda parte do instrumento buscou identificar a percepção e o comportamento da comunidade em relação às dimensões de infraestrutura local, hábitos cotidianos, interatividade social e destinação de resíduos. A primeira dimensão - avaliação da infraestrutura - dedicou-se a produzir informações sobre como os moradores percebem e avaliam o ambiente em que vivem, abordando itens relacionados à educação, saúde, segurança e outros serviços oferecidos à comunidade.
A segunda dimensão, focalizando o comportamento cotidiano, teve como propósito avaliar os hábitos da comunidade, associados a aspectos de comunicação, esporte, alimentação e consumo. A interatividade foi o tema principal da terceira dimensão da pesquisa, dedicando-se a verificar o nível das interações existentes entre as pessoas e as instituições da comunidade, no fito de conhecer o grau de satisfação da população em relação às instituições que exercem determinada liderança na comunidade. A última dimensão, que tratou de questões relacionadas à educação ambiental frente aos hábitos de produção e destinação de resíduos, propôs identificar as principais virtudes e demandas da comunidade no processo de enfrentamento dessas questões.

A coleta de dados possibilitou a construção de indicadores com tendências positivas (potenciais) e negativas (desafios) no contexto socioambiental da comunidade estudada. Nas Tabelas de 2 a 5 é apresentada a distribuição de frequência de todos os itens 
do instrumento aplicado, demonstrando os números ficamente (Figuras de 5 a 8 ) e os indicadores que absolutos e as porcentagens de respostas, de acordo com as alternativas da escala de Likert adotada. À guisa de síntese, os dados estão representados graexpressaram maior relevância para articulação de ações de educação ambiental no campo de estudo encontram-se na Tabela 6.

TABELA 2 - Distribuição de frequência da percepção coletiva sobre a infraestrutura local (dimensão 1).

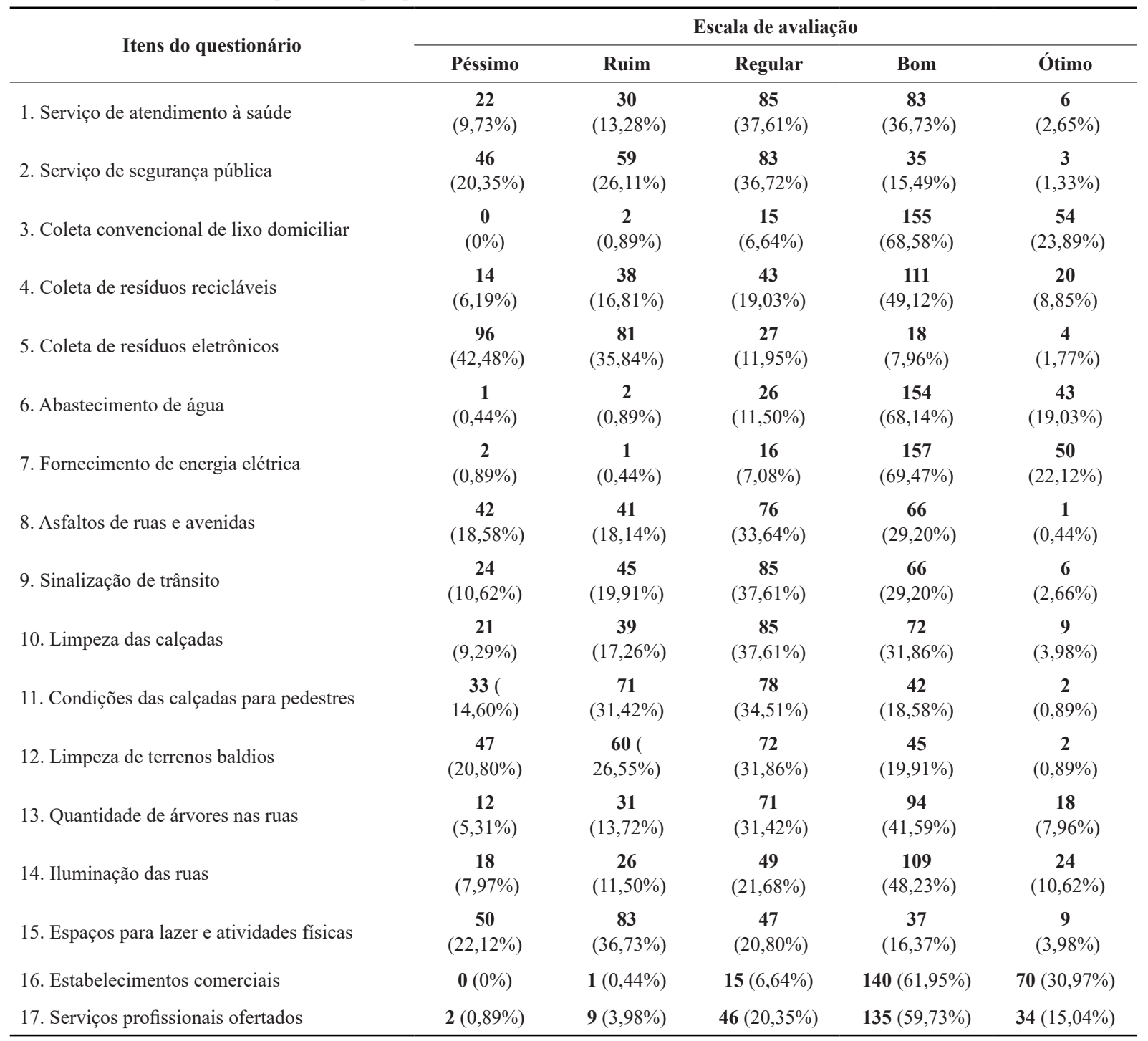

FONTE: Elaborada pelos autores, 2018. 


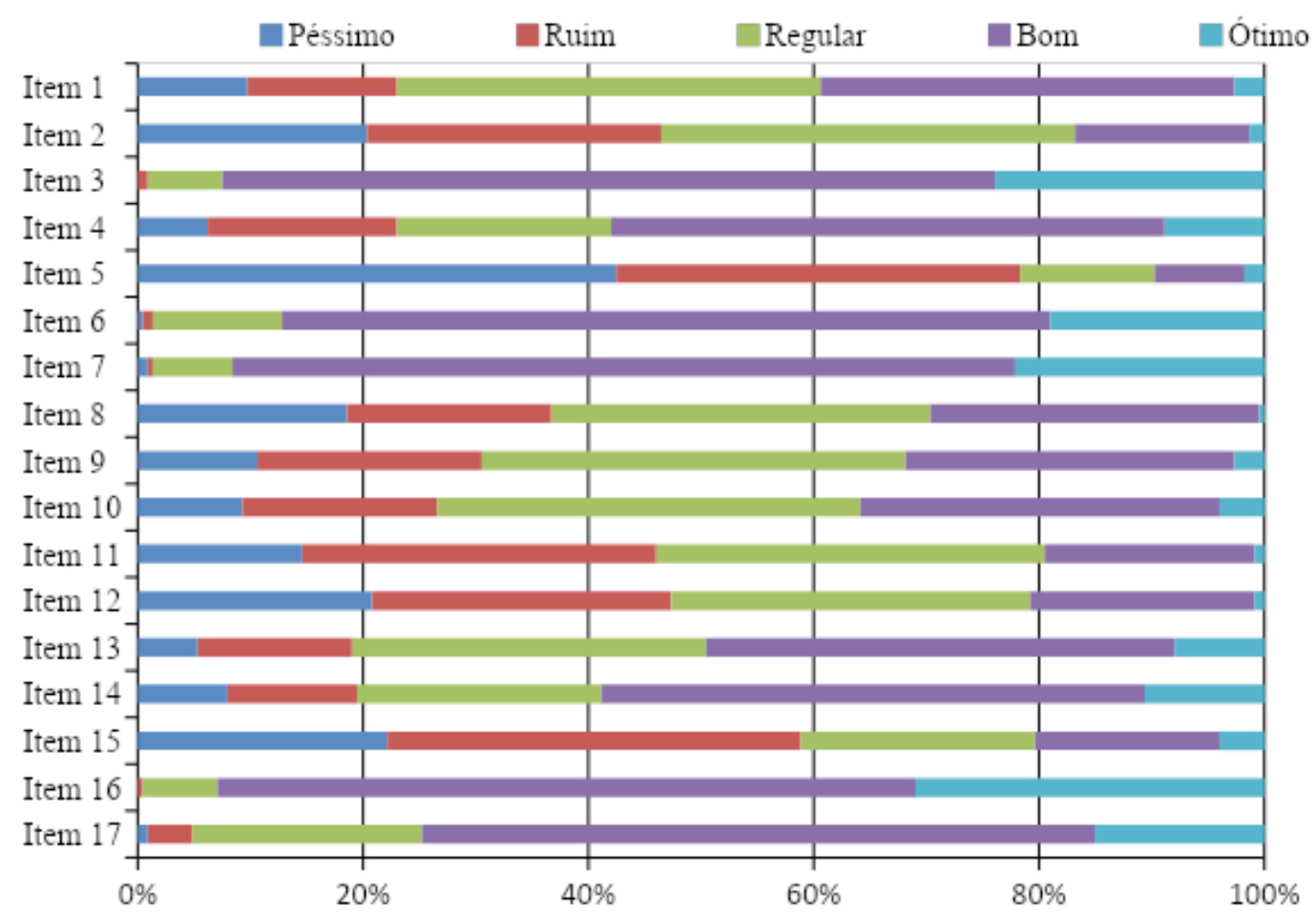

FIGURA 5 - Representação da distribuição de frequência da dimensão 1.

FONTE: Elaborada pelos autores, 2018.

TABELA 3 - Distribuição de frequência da percepção coletiva sobre a infraestrutura local (dimensão 2).

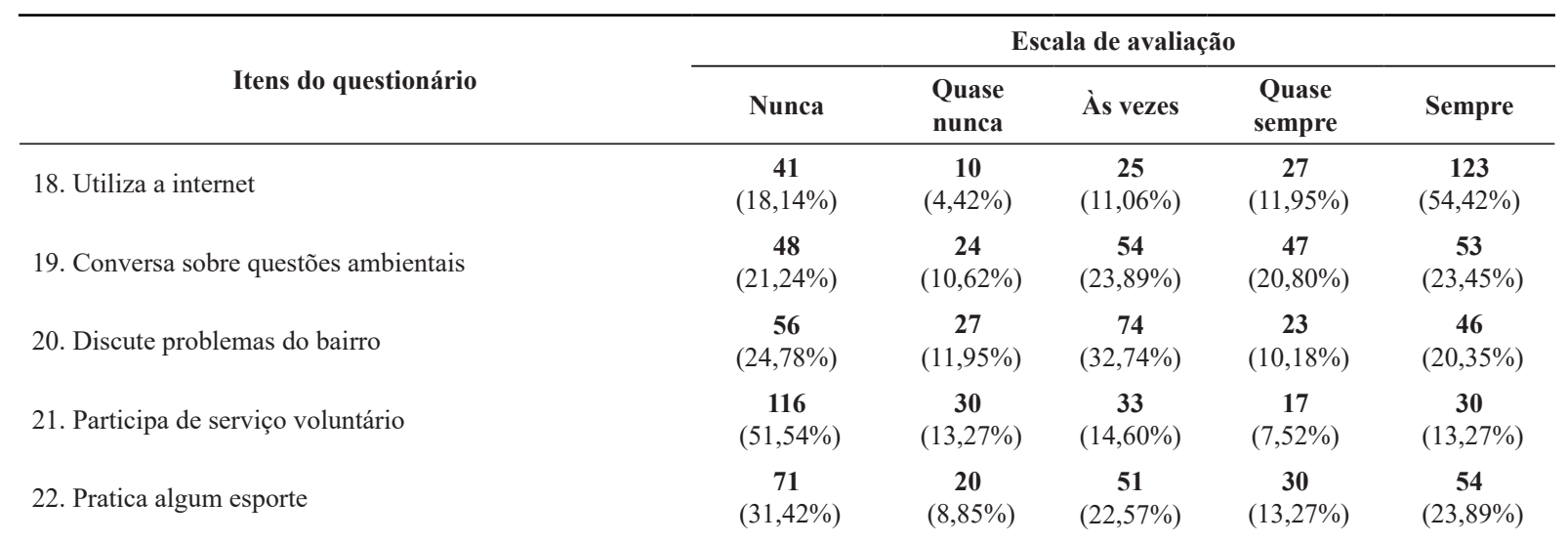


23. Utiliza transporte público

24. Faz compra no próprio bairro

25. Contrata serviços da comunidade

26. Prepara refeições em casa

27. Prioriza compra de frutas e verduras

28. Compra diretamente em hortas

29. Lê rótulos no ato da compra

30. Utiliza sacola fixa

31. Armazena lixo em sacolas plásticas
80

$(35,41 \%)$

2

$(0,88 \%)$

35

$(15,49 \%)$

2

(0,88\%)

1

$(0,44 \%)$

99

(43,81\%)

34

(15,04\%)

115

$(50,89 \%)$

5

(2,21\%)

\section{5}

(19,91\%)

5

(2,21\%)

28

(12,39\%)

0

(0\%)

5

(2,21\%)

42

(18,58\%)

24

$\mathbf{2 4}$
$(10,62 \%)$

26

(11,50\%)

2

$(0,88 \%)$

\section{2}

(18,58\%)

28

(12,39\%)

54

(23,89\%)

4

(1,77\%)

17

(7,52\%)

59

(26,11\%)

71

(31,42\%)

32

(14,16\%)

22

$(9,74 \%)$
17

(7,52\%)

49

(21,68\%)

51

(22,56\%)

43

(19,03\%)

38

(16,81\%)

12

(5,31\%)

36

$(15,93 \%)$

17

(7,52\%)

32

$(14,16 \%)$
42

(18,58\%)

142 (62,83\%)

58 (25,67\%)

$\mathbf{1 7 7}$ (78,32\%)

165 (73,02\%)

14 (6,19\%)

61 (26,99\%)

36 $(15,93 \%)$

165 (73,01\%)

FONTE: Elaborada pelos autores, 2018.

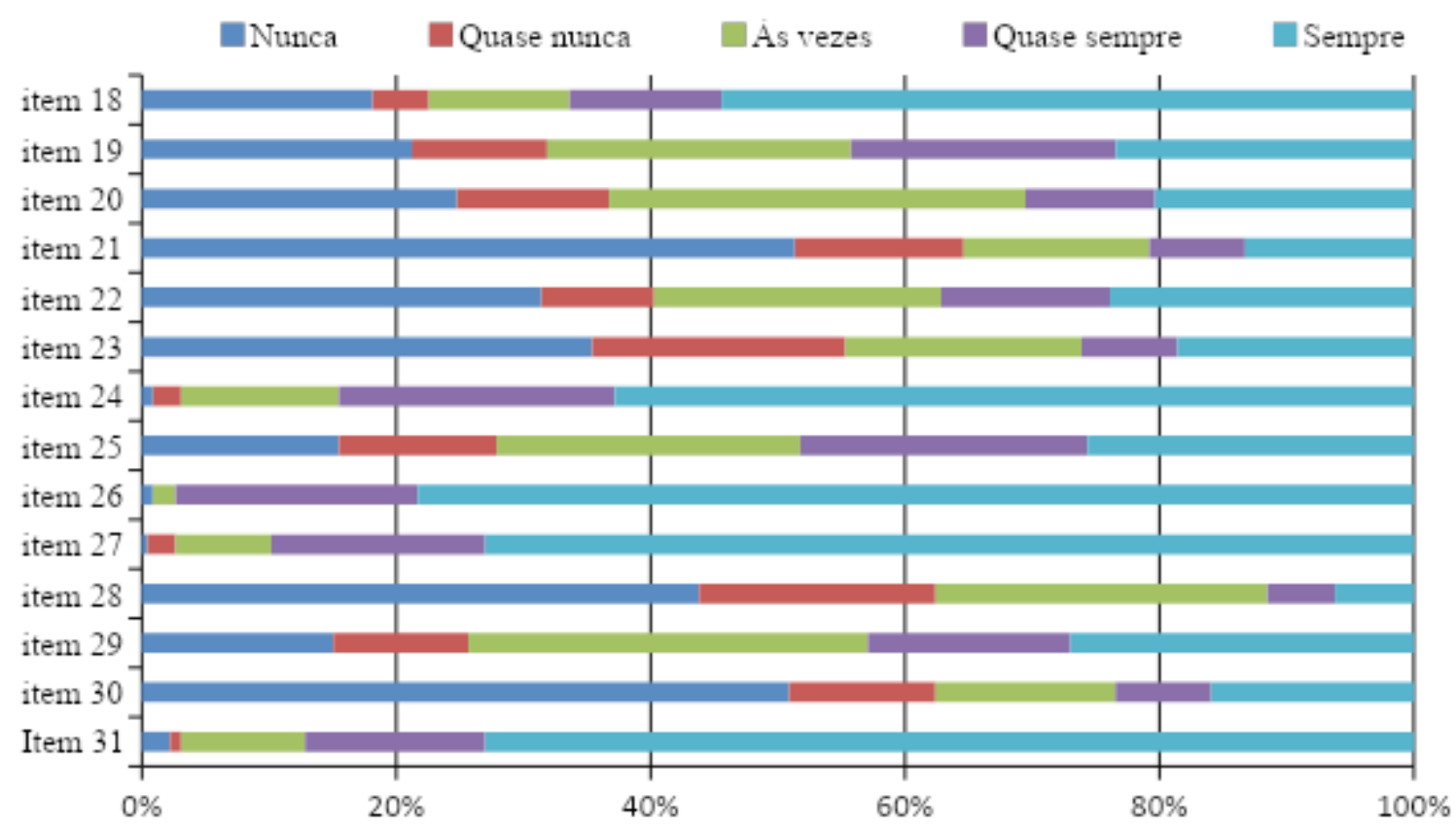

FIGURA 6 - Representação da distribuição de frequência da dimensão 2.

FONTE: Elaborada pelos autores, 2018. 
TABELA 4 - Distribuição de frequência da percepção coletiva sobre a infraestrutura local (dimensão 3).

\begin{tabular}{|c|c|c|c|c|c|}
\hline Itens do questionário & \multicolumn{5}{|c|}{ Escala de avaliação } \\
\hline 32. interação com as universidades & $\begin{array}{c}43 \\
(19,03 \%)\end{array}$ & $\begin{array}{c}\mathbf{6 8} \\
(30,09 \%)\end{array}$ & $\begin{array}{c}73 \\
(32,30 \%)\end{array}$ & $\begin{array}{c}34 \\
(15,04 \%)\end{array}$ & $\begin{array}{c}\mathbf{8} \\
(3,54 \%)\end{array}$ \\
\hline 33. interação com as escolas & $\begin{array}{c}15 \\
(6,64 \%)\end{array}$ & $\begin{array}{c}46 \\
(20,35 \%)\end{array}$ & $\begin{array}{c}64 \\
(28,32 \%)\end{array}$ & $\begin{array}{c}90 \\
(39,82 \%)\end{array}$ & $\begin{array}{c}11 \\
(4,87 \%)\end{array}$ \\
\hline $\begin{array}{l}\text { 35. atuação das empresas frente aos problemas } \\
\text { locais }\end{array}$ & $\begin{array}{c}33 \\
(14,60 \%)\end{array}$ & $\begin{array}{c}91 \\
(40,27 \%)\end{array}$ & $\begin{array}{c}\mathbf{6 8} \\
(30,09 \%)\end{array}$ & $\begin{array}{c}34 \\
(15,04 \%)\end{array}$ & $\begin{array}{c}\mathbf{0} \\
(0 \%)\end{array}$ \\
\hline 36. atuação da associação de moradores & $\begin{array}{c}59 \\
(26,10 \%)\end{array}$ & $\begin{array}{c}78 \\
(34,51 \%)\end{array}$ & $\begin{array}{c}59 \\
(26,10 \%)\end{array}$ & $\begin{array}{c}27 \\
(11,96 \%)\end{array}$ & $\begin{array}{c}3 \\
(1,33 \%)\end{array}$ \\
\hline
\end{tabular}

FONTE: Elaborado pelos autores, 2018.

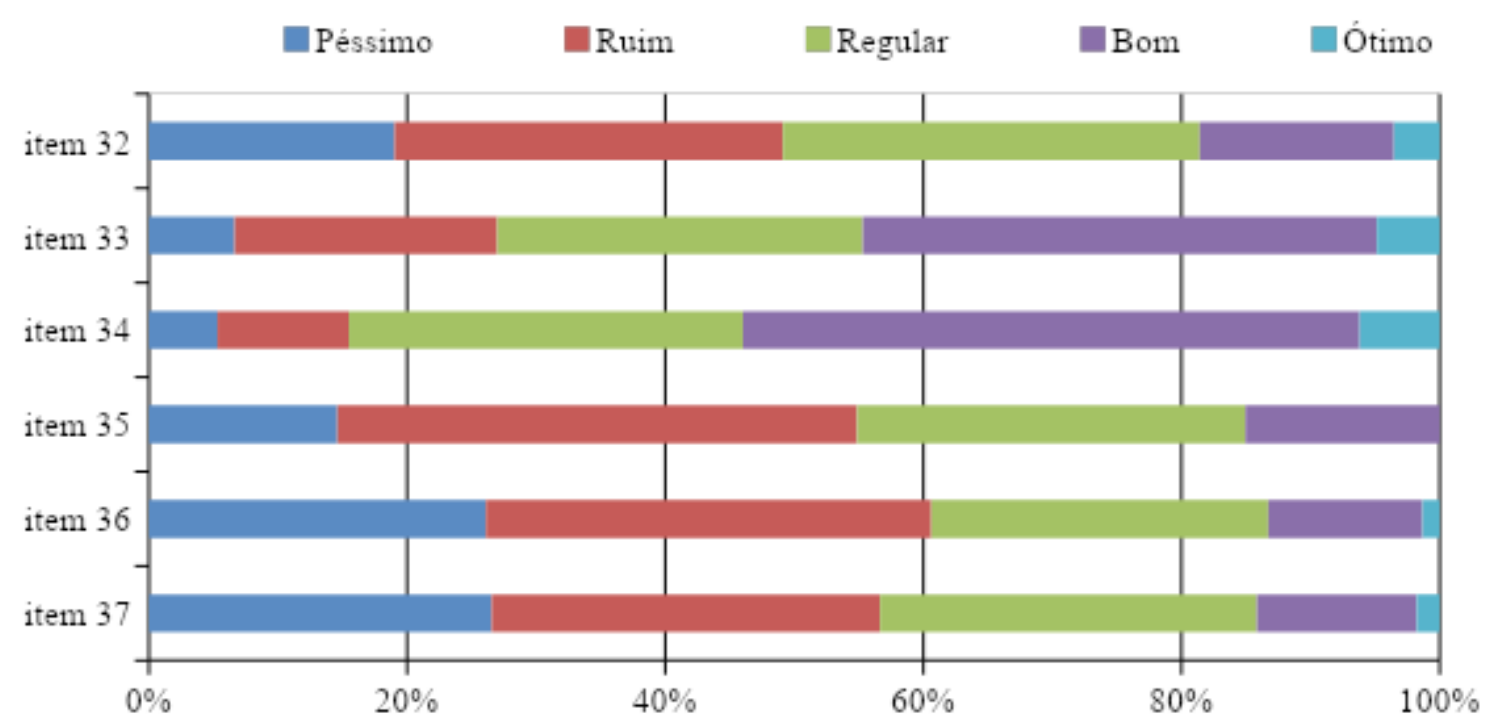

FIGURA 7 - Representação da distribuição de frequência da dimensão 3.

FONTE: Elaborada pelos autores, 2018. 
TABELA 5 - Distribuição de frequência da percepção coletiva sobre a infraestrutura local (dimensão 4).

\begin{tabular}{|c|c|c|c|c|c|}
\hline \multirow[b]{2}{*}{ Itens do questionário } & \multicolumn{5}{|c|}{ Escala de avaliação } \\
\hline & Nunca & $\begin{array}{l}\text { Quase } \\
\text { nunca }\end{array}$ & Às vezes & Quase sempre & Sempre \\
\hline 39. Separação dos resíduos orgânicos & $\begin{array}{c}52 \\
(23,01 \%)\end{array}$ & $\begin{array}{c}17 \\
(7,52 \%)\end{array}$ & $\begin{array}{c}21 \\
(9,29 \%)\end{array}$ & $\begin{array}{c}32 \\
(14,16 \%)\end{array}$ & $\begin{array}{c}104 \\
(46,02 \%)\end{array}$ \\
\hline 41. Destinação de recicláveis para coleta seletiva & $\begin{array}{c}\mathbf{5 6} \\
(24,78 \%)\end{array}$ & $\begin{array}{c}13 \\
(5,75 \%)\end{array}$ & $\begin{array}{c}30 \\
(13,27 \%)\end{array}$ & $\begin{array}{c}\mathbf{2 9} \\
(12,83 \%)\end{array}$ & $\begin{array}{c}\mathbf{9 8} \\
(43,37 \%)\end{array}$ \\
\hline 42. Destinação de orgânicos para compostagem & $\begin{array}{c}154 \\
(68,14 \%)\end{array}$ & $\begin{array}{c}22 \\
(9,73 \%)\end{array}$ & $\begin{array}{c}19 \\
(8,41 \%)\end{array}$ & $\begin{array}{c}7 \\
(3,10 \%)\end{array}$ & $\begin{array}{c}\mathbf{2 4} \\
(10,62 \%)\end{array}$ \\
\hline
\end{tabular}

FONTE: Elaborada pelos autores, 2018.

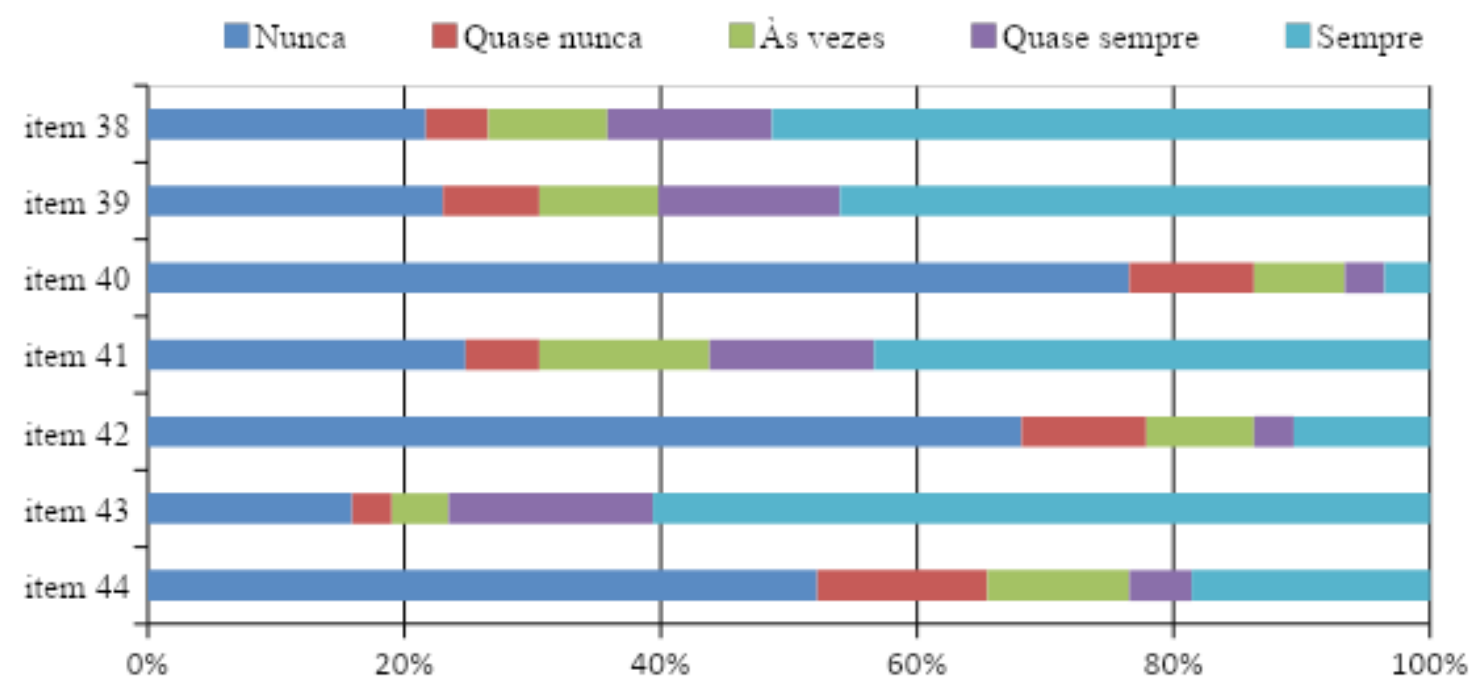

FIGURA 8 - Representação da distribuição de frequência da dimensão 4.

FONTE: Elaborada pelos autores, 2018. 
TABELA 6 - Relação de indicadores do instrumento de pesquisa que apresentaram maior relevância para as ações de educação ambiental na comunidade.

\begin{tabular}{|c|c|c|}
\hline \multicolumn{2}{|c|}{ Indicadores com tendência positiva (potenciais) } & \multirow[t]{2}{*}{$\begin{array}{l}\text { Ótimo/Bom ou Sempre/Frequente- } \\
\text { mente } \\
\end{array}$} \\
\hline Item & Temática & \\
\hline 3 & Serviço de coleta convencional do lixo domiciliar & $92 \%$ \\
\hline 16 & Comércio local & $93 \%$ \\
\hline 26 & Hábito de preparar as refeições em casa & $97 \%$ \\
\hline 27 & Prioridade na compra de frutas e verduras & $90 \%$ \\
\hline 33 & Interação das escolas com a comunidade & $44 \%$ \\
\hline 34 & Interação das igrejas com a comunidade & $54 \%$ \\
\hline 38 & Hábito de separar o material reciclável em casa & $64 \%$ \\
\hline 43 & Destinação do óleo de cozinha saturado para reciclagem & $76 \%$ \\
\hline \multicolumn{2}{|c|}{ Indicadores com tendência negativa (desafios) } & Péssimo/Ruim ou Nunca/Quase nunca \\
\hline 5 & Coleta de resíduos eletrônicos & $76 \%$ \\
\hline 15 & Espaço para lazer e prática de atividades físicas & $59 \%$ \\
\hline 21 & Participação voluntária em atividades solidárias & $64 \%$ \\
\hline 30 & Uso de sacolas fixas durante as compras & $62 \%$ \\
\hline 35 & Participação das empresas nos problemas da comunidade & $54 \%$ \\
\hline 37 & Comunicação entre Prefeitura Municipal e comunidade & $56 \%$ \\
\hline 42 & Destinação de resíduos orgânicos para compostagem & $78 \%$ \\
\hline 44 & Descarte correto de resíduos eletrônicos & $65 \%$ \\
\hline
\end{tabular}

FONTE: Elaborada pelos autores, 2018.

Como parte fundamental do processo participativo, as informações geradas pelo diagnóstico foram compartilhadas com a comunidade. De forma mais específica, a devolutiva aos respondentes do questionário foi realizada por meio de aplicativos móveis e informativo impresso, entregue porta a porta. A socialização das informações, com abrangência à comunidade, foi realizada mediante a criação de uma página eletrônica na internet, que mais tarde constituiu-se um canal de comunicação entre a população e os pesquisadores, assim como contribuiu para o desenvolvimento das futuras intervenções locais. Ademais, o diagnóstico foi compartilhado com os atores sociais por meio de seminários, reuniões, encontros e oficinas, envolvendo moradores, escolas e igrejas da comunidade, cooperativas de recolhedores de recicláveis, gestão pública, universidades, ministério público, parlamentares e outras organizações interessadas pelo tema.

\section{Discussão}

A partir dos resultados da pesquisa social foi possível tecer uma avaliação diagnóstica mais ampla do campo de estudo, com apontamentos sobre os 
principais potenciais e desafios que se apresentam em cada dimensão abordada. Trata-se de um passo importante no processo de articulação social, pois, em consonância com as diretrizes do Caderno Metodológico para ações de Educação Ambiental, um diagnóstico construído com base na percepção dos atores sociais valoriza o conhecimento local e retrata a realidade na qual se pretende atuar (Brasil, 2009).

Nesse sentido, o instrumento de pesquisa contribuiu para identificar aspectos importantes sobre a comunidade. Dentre as caracterizações, observa-se que os índices de escolaridade da população variam entre ensino médio e ensino superior, a maior parte dos moradores residem em moradia própria e são adeptos ao catolicismo ou à doutrina espírita. A pesquisa também revelou que, embora prevaleça período médio de 21 anos de moradia, as pessoas desconhecem a história sobre a origem do bairro e apresentaram dificuldades em indicar um local do bairro de que mais gostam ou que lhes desagrada.

Uma leitura derivada desses indicadores alerta para uma necessidade de estimular os sentimentos de pertença e de afetividade dos moradores com o bairro, fortalecendo assim os aspectos de coletividade e de cuidado com o ambiente em que vivem. São elementos importantes que podem integrar as ações de mobilização comunitária, despertando nas pessoas maior interesse para participação na etapa de intervenção social.

Os itens associados à infraestrutura local apontaram avaliação positiva em relação aos serviços públicos oferecidos à comunidade. Conferiram maior destaque a coleta convencional do lixo domiciliar e o fornecimento de água e energia elétrica. O comércio local foi outro item bem avaliado pelos moradores, o qual foi ratificado pela afirmativa dos respondentes quanto ao hábito de fazer compras nos estabelecimentos comerciais do próprio bairro.

O maior desafio apontado ainda nesta dimensão da pesquisa predominou sobre a questão da coleta de resíduos eletrônicos, revelando que se trata de uma ação pouco trabalhada na comunidade ou que apresenta baixos índices de eficácia. Observa-se que tal situação tende a agravar-se à medida que a comunidade declarou não ter o hábito de separar e destinar apropriadamente esse tipo de material, conforme apontado no levantamento de dados.

A interatividade social, tratada na terceira dimensão do instrumento, revelou que, na ótica dos moradores, as escolas e as igrejas são as instituições que melhor interagem com a comunidade, enquanto universidades, empresas da iniciativa privada, poder público municipal e associação de moradores exercem essa relação social de forma insatisfatória. De acordo com os indicadores, a baixa interatividade entre as empresas locais e a comunidade torna-se mais evidente quando comparados os números positivos em relação ao grau de fidelidade dos moradores no consumo de produtos e serviços dessas empresas e os baixos índices da (des)atenção dada por essas empresas aos problemas locais.

Ainda que sejam instituições de representatividade social, prefeitura e associação de moradores foram apontadas como instituições com deficiências no processo de comunicação social. Já as universidades apresentaram patamar mediano de interatividade, uma vez que sua atuação é pouco percebida na comunidade. Esses indicadores apontam a necessidade de alertar tais instituições sobre a imagem que elas estão passando para a comunidade em seu entorno, despertando o interesse pela busca de alternativas para participação comunitária, assim 
como a necessidade de revisão da proposta de valor de seus empreendimentos.

Por outro lado, as igrejas e as escolas da comunidade assumiram uma posição de maior liderança comunitária, demonstrando potencial de influência para processos de mobilização social e de parceria em ações de intervenção socioambiental no bairro.

Por fim, dado enfoque à produção e destinação dos resíduos urbanos, verificou-se que a comunidade tende a fazer em casa a separação dos materiais recicláveis, disponibilizando-os para a coleta seletiva. Entretanto, percebe-se certo descompasso entre esses indicadores positivos e aqueles resultantes da avaliação sobre o recolhimento de recicláveis que é realizado no bairro, o que enseja melhor investigação nas atividades operacionais desse serviço.

De maneira similar, o ciclo de reciclagem de resíduos orgânicos ocorre com ineficácia, uma vez que as pessoas afirmaram fazer a separação dos restos de alimentos em casa, porém o processo sofre descontinuidade em relação às etapas de coleta e destinação do material. Posto isso, tudo leva a crer que, embora haja separação na origem, os orgânicos seguem para o lixo comum, na qualidade de rejeito. Por outro lado, situação diferente ocorre com o descarte do óleo de cozinha saturado, que se firma como atitude positiva na comunidade. Mais de $80 \%$ dos respondentes declararam não descartar o óleo na rede pública de esgoto, alegando destiná-lo a algum tipo de reutilização.

Com base nesses indicadores socioambientais, as etapas sucessivas orientadas pelo Caderno Metodológico foram conduzidas nos moldes de uma pesquisa-ação participativa, contemplando processos de mobilização social e de intervenção a partir de projetos de educação ambiental envolvendo moradores, lideranças locais, escolas, igrejas, associação de bairro, cooperativa de recolhedores de recicláveis, universidades, dentre outros parceiros.

Entre as articulações desenvolvidas no campo de estudo destacam-se: a realização de uma pesquisa sobre a história da origem da comunidade, culminando na organização de mostras em escolas e outros espaços de convivência do bairro para difundir conhecimento e estimular o sentimento de pertença dos moradores; o desenvolvimento de oficinas de educação ambiental nas escolas, oportunizando a realização de debates sobre os impactos socioambientais em dimensões local, regional e global, buscando assim estimular reflexões críticas sobre o tema e, por fim, a implementação de ações coletivas para enfrentamento das questões relacionadas à destinação dos resíduos eletroeletrônicos na comunidade, cujo resultado culminou na criação de pontos de entrega voluntária dentro da própria comunidade.

\section{Considerações finais}

A realização do diagnóstico acerca das questões socioambientais gerou informações relevantes sobre as percepções, os hábitos e os comportamentos da comunidade estudada, conferindo ao processo investigativo a importância da participação social. $\mathrm{O}$ instrumento possibilitou conhecer melhor a realidade local e suas peculiaridades, de maneira que cada aspecto identificado contribui para o direcionamento das ações de mobilização e intervenção social, conforme preconizado pela metodologia de pesquisa adotada.

A técnica de amostragem por conglomerados ofereceu maior facilidade operacional na coleta de dados, uma vez que a estratégia requer menos recur- 
sos humanos e proporciona agilidade na condução do trabalho de campo. Os resultados evidenciaram os potenciais da comunidade e os principais desafios socioambientais existentes, corroborando os propósitos da etapa de diagnóstico e ratificando a viabilidade de aplicação do instrumento. Contudo, consciente de que o instrumento de pesquisa apresentado não é definitivo, sugere-se que as dimensões sejam ajustadas para diferentes contextos, na busca de melhor entendimento da realidade sobre a qual se pretende atuar.

Conclui-se, portanto, que o instrumento de pesquisa utilizado caracteriza-se como uma potencial ferramenta de avaliação socioambiental, oferecendo subsídios para desenvolvimento de ações qualificadas em educação ambiental. Nesse contexto, a proposta metodológica de diagnóstico participativo enfatiza a relevância do envolvimento das pessoas desde o início do processo investigativo, conferindo à pesquisa social o rigor científico para identificação de cenários, priorização dos problemas e maior assertividade na busca de soluções. Além disso, o instrumento analisado firmou-se como elemento fundamental no processo de socialização de informações com público envolvido, sobretudo para guiar discussões, ações de intervenção e outros estudos futuros.

\section{Referências}

Alcíbar, M. Comunicación pública de la ciencia y la tecnología: una aproximación crítica a su historia conceptual. Arbor, 191(773), p. a242, 2015. doi: 10.3989/ arbor.2015.773n3012

Almeida, R.; Scatena, L. M.; Luz, M. S. Percepção ambiental e políticas públicas - dicotomia e desafios no desenvolvimento da cultura de sustentabilidade. Am- biente \& Sociedade, São Paulo, 20(1), 43-64, 2017. doi: 10.1590/1809-4422ASOC20150004R1V2012017

Atienza, J.; Lujan, J. L. La Imagen Social de las Nuevas Tecnologías Biológicas en España. Madrid: Centro de Investigaciones Sociológicas, Opiniones y actitudes, 1997.

Bittar, M.; Ferreira Jr., A. Ciência e Tecnologia: uma perspectiva histórico-filosófica. In: Hayashi, M. C. P. I.; Rigolin, C. C. D.; Kerbauy, M. T. M. (Orgs.). Sociologia da Ciência: contribuições ao campo CTS. Campinas, SP: Editora Alínea, 2014. p. 13-40.

Bolfarine, H.; Bussab, W. O. Elementos de amostragem. São Paulo: Editora Blucher, 1. ed., 2005.

Bonzi, R. S. Meio século de Primavera Silenciosa: um livro que mudou o mundo. Desenvolvimento e Meio Ambiente, 28, 207-215, 2013. doi: 10.5380/dma.v28i0.31007

Brandão, C. R. A pergunta a várias mãos: a experiência da pesquisa no trabalho do educador. São Paulo: Cortez, 2003.

Brandão, C. R.; Borges, M. C. A pesquisa participante: um momento da educação Popular. Revista de Educação Popular, 6, 51-62, 2007. Disponível em: http://www.seer. ufu.br/index.php/reveducpop/article/view/19988/10662

Brasil. Ministério das Cidades. Secretaria Nacional de Saneamento Ambiental. Caderno metodológico para ações de educação ambiental e mobilização social em saneamento (PEAMSS). Brasília, 2009. Disponível em: http://www. mma.gov.br/images/arquivo/80219/CadernoMetodologico. pdf

Carson, R. Primavera silenciosa. São Paulo: Melhoramentos, 2 ed., 1969.

Coluci, M. Z. O.; Alexandre, N. M. C.; Milani, D. Construção de instrumentos de medida na área da saúde. Ciência e Saúde Coletiva, 20(3), 925-936, 2015. doi: 10.1590/S141381232011000800006

Costa, H. A.; Bursztyn, M. A. A.; Nascimento, E. P. do. Participação Social em Processos de Avaliação Ambiental Estratégica. Sociedade e Estado, 24(1), 89-113, 2009. doi: 10.1590/S0102-69922009000100005

Foltz, F. Five Arguments for Increasing Public Participation in Making Science Policy. Bulletin of Scien- 
ce, Technology \& Societ, 19(2), 117-127, 1999. doi: 10.1177/027046769901900206

Gregolin, J. A. R.; Hoffmann, W. A. M.; Faria, L. I. L. Aspectos metodológicos da prospecção tecnológica para a pesquisa em Ciência, Tecnologia e Sociedade. In: Souza, C. M.; Hayashi, M. C. P. I. (Orgs.). Ciência, Tecnologia e Sociedade: enfoques teóricos e aplicados. São Carlos: Pedro e João Editores, 2008. p. 89-112.

Haddad, N. Metodologia de estudos em ciência da saúde: como planejar, analisar e apresentar um trabalho científico. São Paulo: Roca, 2004.

Hannigan, J. A. Sociologia ambiental: a formação de uma perspectiva social. Lisboa: Piaget, 1997.

Hayashi, M. C. P. I.; Rigolin, C. C. D.; Kerbauy, M. T. M. Apresentação. In: Hayashi, M. C. P. I.; Rigolin, C. C. D.; Kerbauy, M. T. M. (Orgs.). Sociologia da Ciência: contribuições ao campo CTS. Campinas, SP: Editora Alínea, 2014. p. 7-12.

IBGE - Instituto Brasileiro de Geografia e Estatística. Conheça estados e cidades do Brasil, 2018. Disponível em: https://cidades.ibge.gov.br/brasil/mg/uberaba/panorama
López Cerezo, J. A. Participación ciudadana y cultura científica. Arbor, 181(715), 351-362, 2005. doi: 10.3989/ arbor.2005.i715.417

Neder, R. T. Apresentação. Linhas Críticas, 21(45), 265 274, 2015. doi: 10.26512/lc.v21i45.4521

Rowe, G.; Frewer, L. J. Public Participation Methods: A Framework for Evaluation. Science, Technology, \& Human Values, 25(1), 3-29, 2000. doi: 10.1177/016224390002500101

Salles, V. O.; Matos, E. A. S. Á. A Teoria da Complexidade de Edgar Morin e o Ensino de Ciência e Tecnologia. Revista Brasileira de Ensino de Ciência e Tecnologia, 10(1), p. 116-127, 2017. doi: 10.3895/rbect.v10n1.5687

Silveira, D. T.; Córdova, F. P. A pesquisa científica. In: Gerhard, T. E.; Silveira, D. T. (Orgs.). Métodos de pesquisa. Universidade Aberta do Brasil - UAB/UFRGS e Curso de Graduação Tecnológica - Planejamento e Gestão para o Desenvolvimento Rural da SEAD/UFRGS. Porto Alegre: Editora da UFRGS, 2009.

Thiollent, M. Metodologia da Pesquisa-ação. São Paulo: Cortez, 18. ed., 2011. 